\title{
Research on Forecasting Method of Electricity Consumption in the Whole Society Based on Energy Consumption Indicators
}

\author{
Junhui Liu ${ }^{1, a}$, Jiangbo Wang ${ }^{1,2}$, Fangzhao Deng ${ }^{1}$, Hujun Li ${ }^{1}$, Peng Jia ${ }^{1}$, \\ Fang Guo ${ }^{1}$,Shuaijun $\mathrm{Gao}^{3, \mathrm{~b}}$ \\ ${ }^{1}$ State Grid Henan Economic Research Institute, Zhengzhou, 450000, China \\ ${ }^{2}$ School of Electrical Engineering, Wuhan University, 430072, China \\ ${ }^{3}$ Industrial Technology Research Institute, Zhengzhou University, 450001, China \\ aluh5620418@163.com, bsg1142474326@163.com
}

\begin{abstract}
Keywords: energy consumption per GDP, terminal energy consumption, electricity consumption in the whole society, forecasting.

Abstract. Fully considering the government's economic and social development and related energy planning, based on energy consumption per GDP and other binding indicators, the change of electrical energy in terminal energy consumption has been analyzed and the forecasting model of electricity consumption in the whole society has been built. The electricity consumption in the whole society of Henan in 2020 has been successfully forecasted through a specific example. The feasibility and practicability of this forecasting method are verified. This method can provide the basis for power planning and business decision-making.
\end{abstract}

\section{Introduction}

The prediction of power consumption in the whole society is the basic work of power system planning and operation. A variety of forecasting methods based on different starting points are proposed and practiced, which have their own scope and advantages. Such as key industry analysis based on the analysis of the industry changes in electricity consumption and daily average electricity consumption method takes into account the influence of cooling and heating capacity. As the current resource environment constrains and energy efficiency issues are highlighted, the state has introduced a series of energy industry development plans to promote energy transformation and transformation. It is necessary to propose a new forecast method of electricity consumption in the whole society which start from the planning point of view, based on the binding index proposed by the government and consider the structural changes of energy consumption. This method can provide a useful supplement for the selection of the forecast result of electricity consumption in the whole society from the perspective of government planning, and aims to provide decision-making reference for the power enterprises.

\section{Method description}

The development of the national economy and society needs the comprehensive protection of coal, oil, natural gas, electricity and other categories of energy. In order to promote the adjustment of energy structure, protect the ecological environment, enhance the overall efficiency of energy systems, achieve green energy industry healthy sustainable development, the government clearly put forward some constraint index such as the unit GDP energy consumption " the 13th Five-Year Plan for Energy Development " . This method is based on the government plan of economic, social development and energy, besides energy consumption indicators as the breakthrough point to carry out the long-term electricity consumption forecast in the whole society.

Total energy consumption $\mathrm{E}_{1}$. On the base of total energy consumption in current year, the total energy consumption for the target year can be calculated based on the economic development 
indicator proposed by " the 13th Five-Year Plan for National Economy and Social Development " and the unit GDP energy consumption indicator proposed by " the 13th Five-Year Plan for Energy Development " .

Terminal energy consumption $\mathrm{E}_{2}$.

$E_{2}=E_{e}+E_{o}$

In formula (1), $\mathrm{E}_{\mathrm{e}}$ - terminal electric energy consumption; $E_{o}$ - terminal other energy consumption.

$E_{e}=\left(E_{Q}-E_{C}-E_{W}\right)$

In formula (2), $E_{Q^{-}}$whole society electricity consumption; $E_{C^{-}}$auxiliary power consumption; $E_{W^{-}}$ electric quantity of network losses; $\alpha$ - power equivalent, that is 0.1229 kilogram of standard coal equivalent /kilowatt hour.

$E_{o}=\left(E_{1}-\gamma E_{Q}\right) * \beta$

In formula (3), $\beta$-conversion factor of other energy processing, which is about 0.9 in the literature; $\gamma$ - coal consumption of power generation.

The proportion of electrical energy to terminal energy consumption $\xi$. The annual value of this coefficient can be calculated from the statistical data, the target year value can be obtained by methods such as trend extrapolation.

$$
\xi=E_{e} / E_{2}=E_{e} /\left(E_{e}+E_{o}\right)
$$

According to formula (2), (3), (4), the analytical formula of electricity consumption can be get.

$E_{Q}=\frac{\beta \xi E_{1}+\alpha(1-\xi)\left(E_{C}+E_{W}\right)}{\alpha(1-\xi)+\gamma \beta \xi}$

It concrete ideas are as follows: First, according to the forecast of the province's GDP growth level and ten thousands GDP energy consumption trend, get the total energy consumption; Secondly, based on the proportion of electric energy consumption in the terminal energy consumption over the years to predict the level of its development trend, and then through the formula (5) to calculate the total electricity consumption.

\section{Example analysis}

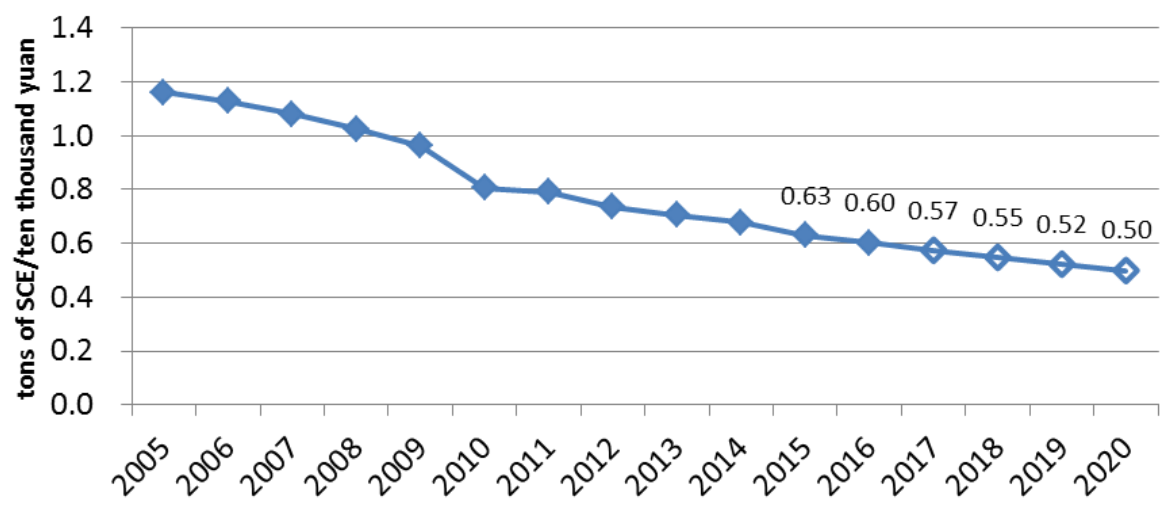

Fig. 1 2005-2020 unit GDP energy consumption trend in Henan Province (2010 comparable price)

According to " the 13th Five-Year Plan for National Economic and Social Development in Henan Province " , the province's economy maintained a high rate of growth, with an average annual growth rate of GDP higher than the national average of 1 percentage point or more. The forecast value of the province's GDP in 2020 (2010 comparable price) is about 5.40 trillion yuan. Since the "Twelfth FiveYear Plan", Henan Province has accelerated the transformation of development mode, industrial transformation and upgrading made significant progress and the province's economic development quality and efficiency continue to be improved, by 2016 the province's unit GDP energy consumption of 0.6 tons of standard coal /ten thousand yuan.

The government in " the 13th Five-Year Plan for Energy Development " put forward constrain index that the national unit GDP energy consumption compared to 2015 decreased about $15 \%$ by 2020. On this basis, the unit GDP energy consumption fell by an annual average of about $3.2 \%$ during 
the "13th Five-Year". Taking into account during the "12th Five-Year" Henan province has completed the national emission reduction targets a year ahead of schedule, It is expected that during the "13th Five-Year", the province unit GDP energy consumption will decline by more than the national average, with an average annual decline of about $4.5 \%$. This value is expected to be 0.50 tons of standard coal equivalent/ ten thousand yuan in 2020 .

Combined with the economic development goals and energy consumption trends of the province, the total energy consumption of the province is expected to be 0.267 billion tons of standard coal equivalent by 2020 .

Table 1 The total energy consumption forecast of Henan province by 2020

\begin{tabular}{ccccc}
\hline Year & $\begin{array}{c}\text { Gross } \\
\text { product(Trillion } \\
\text { yuan) }\end{array}$ & $\begin{array}{c}\text { Growth } \\
\text { index(last } \\
\text { year=100) }\end{array}$ & $\begin{array}{c}\text { Unit GDP energy } \\
\text { consumption(tons of standard } \\
\text { coal /ten thousand yuan) }\end{array}$ & $\begin{array}{c}\text { Total energy } \\
\text { consumption(hundred } \\
\text { million standard coal) }\end{array}$ \\
\hline 2015 & 3.66 & 108.3 & 0.63 & 2.32 \\
2016 & 3.96 & 108.1 & 0.60 & 2.38 \\
2017 & 4.28 & 108.2 & 0.57 & 2.45 \\
2018 & 4.63 & 108.0 & 0.55 & 2.53 \\
2019 & 4.99 & 108.0 & 0.52 & 2.60 \\
2020 & 5.40 & 108.2 & 0.50 & 2.67 \\
\hline
\end{tabular}

Note: GDP is comparable in 2010

Taking into account the upgrading of industrial structure, the gradual improvement of electrification level of urban and rural residents, and the in-depth advancement of electric energy, The province's electric energy accounts for a proportion of terminal energy consumption increased year by year. According to the calculation, in 2015 and 2016 the province's electric energy share of terminal energy consumption is about $21.7 \%, 22 \%$, this proportion will rise further to $23.7 \%$ in 2020 .

Table 2 The forecast of electricity consumption of the whole society in Henan province by 2020

\begin{tabular}{ccccc}
\hline Year & $\begin{array}{c}\text { Electric energy } \\
\text { accounted for the } \\
\text { proportion of terminal } \\
\text { energy }\end{array}$ & $\begin{array}{c}\text { Terminal energy } \\
\text { consumption(hundred } \\
\text { million standard coal) }\end{array}$ & $\begin{array}{c}\text { Electricity consumption in } \\
\text { whole society(Billion } \\
\text { kilowatt hours) }\end{array}$ & Growth rate \\
\hline 2015 & $21.7 \%$ & 1.63 & 288.0 & $-1.4 \%$ \\
2016 & $22.0 \%$ & 1.67 & 298.9 & $3.8 \%$ \\
2017 & $22.4 \%$ & 1.72 & 313.7 & $4.9 \%$ \\
2018 & $22.8 \%$ & 1.77 & 327.3 & $4.4 \%$ \\
2019 & $23.2 \%$ & 1.81 & 341.5 & $4.4 \%$ \\
2020 & $23.7 \%$ & 1.85 & 357.3 & $4.6 \%$ \\
\hline
\end{tabular}

According to the above boundary conditions, it is estimated that in 2020 the province's total energy consumption of 118 million tons of standard coal, the whole society electricity consumption of 357.3 billion kwh, the growth rate of $4.6 \%$.

\section{Summary}

(1) The prediction method based on energy consumption index in this paper gives full consideration to the government's economic, social development and the related planning of energy industry, and is suitable for the prediction of electricity consumption in the medium and long term. It can predict the total annual electricity consumption from year to year.

(2) The boundary condition of the method is clear and the calculation method is explicit. According to the example, in 2020 the whole society electricity consumption of Henan is 357.3 billion kwh and the average annual growth rate in the "13th Five-Year" is $4.4 \%$.

(3) Considering the promotion of technological progress factors and the replacement of electricity, the prediction results of this method may be low, which is suitable as a low level scheme. 


\section{References}

[1]. Zhou Qi, Chen Quan, Jiang Nan, et al. Study on the prediction method of total social electricity consumption based on macroeconomic indicators. Jiangsu science and technology information. Vol. 23 (2015) No. 11, p. 52-53

[2]. Lv Fei, Hu Pengfei. Forecast analysis of electricity consumption in whole society of Hubei Province Based on grey system theory. Hubei electric power. Vol. 12 (2014) No. 12, p. 67-70.

[3]. Wei Chenjun baby, Yang Guiyuan, Yuan Hongjun. GIOWA based operator of the Anhui province's total electricity consumption forecasting. Journal of Jiaxing University. Vol. 29 (2017) No. 1, p. 57-63.

[4]. Ding Hao, Rong Rong. Prediction model and multiple linear regression based on the electricity consumption in Shandong. Henan Science. Vol. 9 (2013) No. 2, p. 1535-1539.

[5]. Rao Guo Liang, Liangping. Support vector machines and their application in the prediction of total social electricity consumption. Guangdong electric power. Vol. 21 (2008) No. 11, p. 22-24.

[6]. Ye Meng. Study on the prediction of social electricity consumption based on Grey Relational Analysis and regression analysis. Value engineering. Vol. 29 (2010) No. 36, p. 211-212.

[7]. Ding Haijing. Multivariate statistical analysis and prediction of electricity consumption in the whole society based on SPSS software. Young science: Teacher Edition. Vol. 35 (2014) No. 5, p. $56-59$.

[8]. Zhang Zheng, Wang Xiaojia. Forecast of power consumption of GA-SVR based on least absolute deviation. Journal of University of Electronic Science and technology of China (SOCIAL SCIENCE EDITION). Vol. 6 (2013) No. 6, p. 25-29.

[9]. Shen Jianxin, Yang Shanlin. Power consumption prediction of particle swarm optimization (SVM) in the perspective of smart grid. Journal of science and technology management. Vol. 33 (2013) No. 11, p. 235-238. 